\title{
Designing a Need Based Social Protection Intervention Package for Children and Adolescents Living with HIV and AIDS in Ghana -An Eclectic Perspective on Desired Social Protection Intervention Package/Framework
}

\author{
Seth Christopher Yaw Appiah1,2* (), Adeyemi Olu Adekunle3 ${ }^{3}$ Adesina Oladokun3, \\ Jonathan Mensah Dapaah², Karikari Mensah Nicholas ${ }^{4}$ \\ ${ }^{1}$ Pan African University Institute of Life and Earth Sciences Including Health and Agriculture University of Ibadan (PAULESI), \\ Ibadan, Nigeria \\ ${ }^{2}$ Department of Sociology and Social Work, Faculty of Social Sciences, Kumasi College of Humanities and Social Science, \\ Nkrumah University of Science and Technology, Kumasi, Ghana \\ ${ }^{3}$ Department of Obstetrics and Gynecology, College of Medicine, University of Ibadan, Ibadan, Nigeria \\ ${ }^{4}$ Public Health Unit, Komfo Anokye Teaching Hospital, Kumasi, Ghana \\ Email: *sychrist2007@gmail.com
}

How to cite this paper: Appiah, S.C.Y., Adekunle, A.O., Oladokun, A., Dapaah, J.M. and Nicholas, K.M. (2019) Designing a Need Based Social Protection Intervention Package for Children and Adolescents Living with HIV and AIDS in Ghana-An Eclectic Perspective on Desired Social Protection Intervention Package/Framework. Health, 11, 1396-1413.

https://doi.org/10.4236/health.2019.1110107

Received: September 16, 2019

Accepted: October 20, 2019

Published: October 23, 2019

Copyright $\odot 2019$ by author(s) and Scientific Research Publishing Inc. This work is licensed under the Creative Commons Attribution International License (CC BY 4.0).

http://creativecommons.org/licenses/by/4.0/

\section{Open Access}

\begin{abstract}
Background: Designing a need-based social protection intervention for children comes as comprehensive tool for addressing the overall quality of life of HIV positive children. Not much has been examined on what constitute the desired social protection framework for HIV positive children. Methods: This study was informed by a qualitative descriptive exploratory design approach. The study drew insights from the shared perspectives of 27 participants sampled from positive HIV status disclosed children-10 - 17 years, healthcare workers, Social and Development worker, HIV positive caregivers and parents from 7 ART clinics in rural and urban Brong Ahafo and Ashanti regions of Ghana. Data was collected through interviews and two focus group discussions with study participants. Drawing on the emerged themes from the transcripts, thematic content analysis was used to analyze the data using comparative thematic framework approach. Findings: The eclectic perspectives on the type of social protection policy/intervention preferred demonstrated the need for an interrelated and integrated social protection policy. This should not be designed in isolation towards addressing the child vulnerability. The study found that social protection policies aimed at addressing vulnerability levels of children should consider the dual vulnerability situa-
\end{abstract}


tion within which HIV positive children and adolescents are located. A set of unique specific tailored approach and package reflecting minimum combination social protection package to HIV positive children was considered essential for inclusion. The themes that emerged covered social policy/intervention package inclusive of a disease ending/eradication intervention package, cash transfer for children and their caregivers, free comprehensive health insurance integrating all consultancy and laboratory services charges, direct food supplements supply and nutritional support, research, target specified with evidenced-based monitoring. Counseling support and preferential treatment for children visiting ART for treatment were to be included. Conclusion: Combination social protection intervention packages remain the pathway to yielding maximum dividends on any social intervention that seeks to address the vulnerability levels of HIV positive children in Ghana. This should be designed taking into consideration the preference of the main target beneficiaries (HIV positive children) while accounting for the inclusion of the technical expertise of implementing stakeholders in the policy design from conceptualization to evaluation.

\section{Keywords}

Social Protection, HIV and AIDS Infected Children, Adolescent's, Intervention, Ghana

\section{Background}

Sub-Saharan Africa continues to share the greatest number of HIV and AIDS infected children despite the gains made globally in addressing the HIV/AIDS epidemic [1]. A multi sectoral approach and perspectives have been shared on how to address the multiplicity of challenges that comes along with caring for HIV and AIDS infected children. This has been due to the increased survival of children resulting improved medication. This has necessitated that stakeholders refocus attention not only on biomedical approaches to treatment and prevention but also livelihood and socio-behavioural dimensions of the illness. The search for a combination intervention to address the needs of HIV and AIDS infected children due to the multidimensional effect of HIV illness on them has been a long-standing academic inquiry.

Scholars such as McCord and Himmelstine and Pettifor and colleagues have reiterated such calls [2] [3]. In 2004, the United States President's Emergency Plan for AIDS Relief (PEPFAR) initiated a Public-Private Partnered intervention in ten African countries and dubbed the intervention Determined, Resilient, Empowered, AIDS-free, Mentored and Safe (DREAMS).

However, Ghana was not included in the programme because the programme was implemented for adolescent girls in high HIV burden countries within the Sub-Saharan Africa [1]. This intervention brings to the fore how the need to design cross approach intervention has been earmarked on the international child 
and adolescent HIV and AIDS agenda. However, the bigger focus of the DREAM intervention was on HIV prevention.

The necessity of designing evidence-based interventions to address cross cutting issues for HIV positive children has been justified elsewhere [4]. It has been found that standalone single intervention offers little results in addressing the multifaceted vulnerability context factors of HIV positive children [4] [5]. This is as a result of the complex factors that HIV and AIDS positive children find themselves.

There is evidence that suggests that, combination social protection interventions are able to reduce child vulnerability levels [5]. In some reported studies, these combination interventions ought to include economic, social and biomedical packages. However, the generic mention of such packages makes it difficult in identifying the specific composition of package that will yield the required reduction in child vulnerability levels. This is because, several interventions come under each of the thematic programmes that have been noted to yield positive outcomes in reducing child vulnerability. International child focused organizations such as UNICEF posits that, designing such HIV positive social interventions should be inclusive and as well have education and health packages [6]. In Ghana, significant number of children continue to live in vulnerable context with less holistic social support interventions designed for them [7].

Despite the acknowledged impact of Ghana Livelihood Empowerment Against Poverty programme in offering social protection by improving the wellbeing of orphans and vulnerable children, the entire spectrum of the intervention reaching HIV positive children has not been analysed [7] [8] [9]. The unique needs of such vulnerable population in terms of programme design and implementation remains absent. The specific tailored social protection intervention that meets the needs of all stakeholders who directly address the vulnerability levels of HIV positive children are difficult to come by among studies reporting on social protection for HIV children in Ghana.

It remains contested on what the nature of social protection programmes for HIV positive children ought to be for Ghanaian HIV and AIDS infected children. A minimum standard package of what best fit, acceptable and evidence based package is needed to address the double vulnerability space of HIV and AIDS infected children. This calls for an empirical study of what is desired. In this study, an attempt is made to find out from stakeholders including children HIV and AIDS positive children, caregivers, positive HIV and AIDS parents, social workers, medical doctors, nutritionist and clinical nurses on the minimum package that is desired to be included in any social protection policy framework for HIV and AIDS infected children.

\section{Methods}

\subsection{Setting}

The study was carried out in the Ashanti and Brong Ahafo regions of Ghana 
between March 2018 and June 2019. The two regions have been consistent in the past 3 years in recording higher national HIV prevalence levels in Ghana. In 2018, Bono region recorded an HIV prevalence of 2.48 per cent while the Ahafo region recorded $2.66 \%$ in HIV prevalence. The prevalence suggests that according to the previous ten regions of Ghana, the Brong Ahafo topped in the HIV prevalence rates in Ghana followed by the Ashanti region. According to the new 16 regions of Ghana, the highest prevalence was recorded by Ahafo region (2.66\%) followed by Bono region (2.48\%) and Ashanti region (1.9\%) [10]. The healthcare providers, positive children and caregiver interviewees were recruited from $7 \mathrm{HIV}$ and AIDS clinics from the two regions. Recruitments were carried out from the health centre except the Social welfare officer.

\subsection{Study Design, Sampling and Participant Selection}

The study adopted a phenomenological qualitative design to elicit the views and perspectives of the various stakeholders by virtue of their daily working engagement, care, uptake of HIV and AIDS services and having to live with HIV and AIDS. The phenomenological approach enabled the researchers to situate the study within the individual own social experiences and to understand their own appraisal of the issues [11].

The sampling strategy was purposive. A total of 27 participants were enrolled in the study through purposive sampling technique. The inclusion criterion was informed by being a principal stakeholder in HIV prevention and care for HIV and AIDS infected children. The study participants were recruited from diverse backgrounds as well as rural and urban locations from where they work from or their facility of operation located. After pre-meeting arrangements with the participants, the first author sought consent from all persons meeting the eligibility criteria. A day and time was fixed and the interview venue was scheduled.

\section{Participant Recruitment and Data Collection}

Two approaches to data collection were adopted. The first approach to the data collection was the conduct of Focus Group Discussions. Two Focus Group Discussion (FGD) were held. One FGD was held in the Holy Family Hospital presence in Techiman in the Brong Ahafo region whilst the second FGD was held at the Komfo Anokye Teaching Hospital, Kumasi in the Ashanti region of Ghana. After consent had been sought from both the facility managers in the case of health care workers, the researcher and another trained interviewee commenced the interviews.

The interviews were conducted in very conducive atmosphere in the natural settings of the study participants. The interviews were conducted in both Asante Twi, which are the predominant language in the two regions as well as English language, which is the official language of use in Ghana.

The rational was to allow participants the freedom and confidence to communicate their responses to the questions asked. Field notes in support of the interviews were taken. The trained data collectors asked probing questions to allow 
for clarification responses from participants using open ended technique. Each interview sessions lasted between 13 - 25 minutes. The key informant's interviews were conducted at the offices of the key informants. Whiles the health care professional's interviews was conducted in the ART clinics, the LEAP officers, Social Welfare officers and Ministry of Gender and Social Protection had their interview session in their offices at the district and regional level.

Key informants opinions on existing social protection interventions for HIV infected children, the impact of existing social protection on the wellbeing of children and the challenges in their effectiveness were explored. The central issue elicited was on the desired social intervention package that was preferred towards designing social protection policy for HIV and AIDS infected children. The study protocol was approved by the Ghana Heath Service Ethics Review Committee with approval number GHS-ERC number: 05/06/17 and the University of Ibadan Ethics committee with approval number: UI/EC/17/0490.

\subsection{Data Processing and Analysis}

Data was collected was done by using a tape recorder to record all the interviews. The recorded interviews and FGD sessions were later transcribed verbatim. Two persons including the research assistant and the lead author transcribe the data independently. The lead author read through all the transcribed data, explored the repetitive narrative, triangulate different themes that are convergent and those that diverge after extensive reading.

The interviews transcribed are supported with the field notes for the analysis. The researchers adopted the open data coding approach to code the categories through the identification of categories and conceptual properties description. The emerged themes are therefore presented guided by an interpretative reasoning and narrative as the phenomenological approach suggest. The sub themes have been linked with the dominant these and presented as the study findings [12] [13] [14].

\section{Results}

\section{Background characteristics of enrolled interviewees and Focus group discussants}

The presented background characteristics in Table 1 shows the eclectic focus in exploring the best fit for purpose social protection intervention desired and adequate for HIV positive children. The nature of professional backgrounds involved reflects the integrated responses anticipated.

From Table 1, nine HIV positive children made up of six males and 3 females were interviewed. Three of the children involved in the in-depth interviews were from the Ashanti region. Three of the children were in Senior High School, three in Junior High School, two in Primary School and one not enrolled in school.

A total of 11 key informant interviews were conducted. Key informant interviews were held with nine (9) healthcare workings directly engaged in ART clin- 
ic and child and adolescent HIV care and management and 2 officers involved in policy and welfare issues for HIV positive children. In all, six of the key informant's interviews were conducted with persons from Brong Ahafo region and five from the Ashanti region. The key informant was conducted with one Medical Doctor, one nutritionist one Social Welfare Officer, One NACP officer, two ART facility/unit managers, two ART data managers, two nurses/adherence counsellors and one HIV positive person support group leader (Model of Hope member).The results are presented in Table 1.

Table 1. Background characteristics of interviewees and focus group discussant.

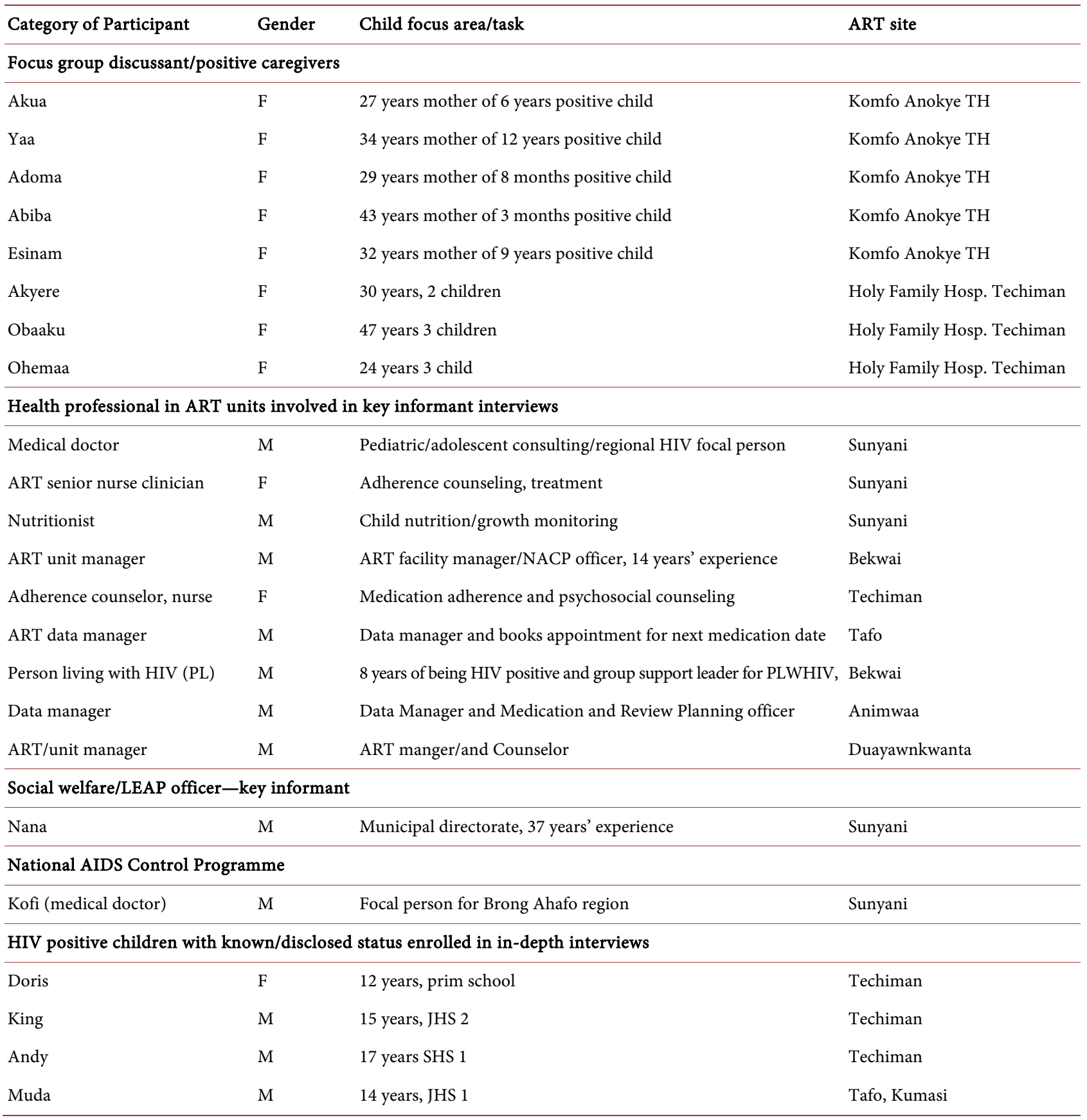


Continued

\begin{tabular}{|c|c|c|c|}
\hline Little & M & 17 years, SHS 1 & Sunyani \\
\hline Sandy & $\mathrm{F}$ & 16 years, SHS 1 & Sunyani \\
\hline Mariam & $\mathrm{F}$ & 15 years, JHS 2 & Sunyani \\
\hline Brother & M & 14 years, prim class 6 & Bekwai \\
\hline Joe & M & 10 years, no schooling & Bekwai \\
\hline
\end{tabular}

*The names used in Table 1 are pseudonyms and are not the real names of the study participants, $\mathrm{RH}=\mathrm{Regional} \mathrm{Hospital}$, TH $=$ Teaching Hospital, $\mathrm{F}=$ Female, $\mathrm{M}=$ Male.

\section{Emerged themes}

The themes that surfaced relative to the ideal social intervention package did not appear distant from each stakeholder. They were rather confirmatory and eclectic. All the stakeholders were corroborative on the need for a combination social protection intervention to address the varied need of HIV positive children. The desired limited social intervention package was proposed to include Disease ending/eradication intervention package.

\section{Disease ending/eradication intervention package}

A dominant theme that kept recurring for already disclosed HIV positive children was an intervention package geared towards disease eradicating. The need for the inclusion of this package was shared among nearly all the positive children interviewed demonstrating how uncomfortable they were with the HIV disease. Despite the first mention of an intervention that will cure their illness, their desire for other support was also reiterated. How HIV positive children considered efforts at entirely eradicating HIV disease as a social protection intervention re-emphasized their discomforting experience of the HIV illness. This stemmed from their accustomed situation of frequent medication intake which had oriented their minds to a quest for medication that will finally do away with HIV virus from their body. When asked about the ideal type of social support or intervention package that positive children expected from policy enactors, it was posited:

"Ohhhh it should be medicines that can cause the illness to go and leave me entirely and also now the help that my grandmother is supporting me if someone can come and support her. Now she supports my school, feeding, if someone can come a support me in school."-perinatally infected boy 15, Brong Ahafo.

Another positive child expressing her topmost desired social protection policy intervention did not mince to indicate her anticipation for disease ending intervention. She shared:

"I need some people to help me to be able to overcome or do away with the illness. Since my childhood, my mother had been picking my medication for me, I used to live with my mother. It's been five years since I came to 
live in Techiman. I attend public school. We don't pay canteen. [.....] It is only the illness that is affecting me." - 12 year old female perinatally infected child, Brong Ahafo.

In furtherance to this view, another positive status disclosed child added:

"...If there is any support or intervention for us, it should be how to eradicate this disease... [ what else] this is what is what I have in mind as desired, an intervention that will help eradicate the HIV disease."-male 17 years, SHS 2 student, Sunyani Brong Ahafo region.

Though not appearing to be directly related to social protection intervention, the unique quest for particular anticipatory social support to avoid a seaming fear and uncertainly was highlighted. This had to do with the opportunity for HIV positive children to be able to give birth in the future. In a particular case, a 15 year old child showed that his greatest concern was how he would be able to get the needed support system that would make him to be able to give birth when he grows up. This request for such a social support was possibly made out of an uninformed position that HIV positive persons could possibly not give birth:

"Ohhh My grandmother keeps telling me that her only daughter is dead and am the only family she has (Grandmother had 1 daughter) so is she is waiting for me to grow and marry and have her grandchild, so that's my focus how I will be able to deliver her that concern." - perinatally infected boy 15, Brong Ahafo.

Another 17 year old student worried if there were such provisions to cater for their fertility needs queried:

"I see the illness does not help, and also I have been thinking about having this illness, so if I grow and get married and give birth, will my child also contract the illness (interviewer observes that child looks disturbed and worried and very lean in growth)"-male positive status disclosed child, SHS 2 student, Sunyani Brong Ahafo.

Similarly, on the need for prioritization of medication in any social protection/social support policy framework design, the call for a systematized well-structured consistent medication supply was highlighted:

"I want to say that for the illness, the ARV medication should come on time so that each child will be able to get his or her own so that the disease will finally will be eradicated."-male 14 years, Tafo, Kumasi Ashanti region.

\section{Cash transfer for children and their caregivers}

Forcefully desired is the need for a cash transfer component imbedded in any social intervention package. Accordingly some shared that the government support in its LEAP programme should be directed mostly to households of HIV positive children:

"Hmmm, for me my own is that now for the workers we work but our salaries are not enough, sometimes, you won't get all for them but we need to 
make sure that the child has to eat well, I get short of money all time,..yes real cash money because we are parents who know what it ....yes the $L E A P$... they should support we rather on the leap so the leap is not given to other persons households but we caregivers of HIV positive children, Its exactly as my sister has said....in terms of direct money to us to cater for the children."-FGD participants, Techiman, Bring Ahafo region.

A sub theme that emerged under the cash transfer was the provision of educational support. However, the need to include educational support was mentioned by only one among all the stakeholders interviewed:

"All I need is that they will be able to help us with the medication and also support mw with my school, so I would be able to buy my school books and other things."

\section{Free comprehensive health insurance integrating laboratory services char-} ges

Comprehensive health insurance that covers all laboratory component not only OPDs and consultancy fees was desired. Though some parents and children affirmed they had health insurance, it covered very minimal components of their health needs. Despite the challenges of positive parents and children having to be on the national health insurance, none of the services offered on the national health insurance covers for laboratories that are compulsory to be run on the HIV infected children such as Liver function test and others. Any social intervention package, it was advocated, should consider making all laboratory tests for HIV positive children free or covered by the national health insurance.

Some positive caregivers shared:

"What my sister is saying is true, if the health insurance could even cover the labs we would have had a breathing space. Some the labs cost as much as 300 cedis, we just can afford it. If you ask for help from someone they will ask that are you using the money for and you can't tell them. And if you don't bring the labs to the clinic, the doctors get furious. They will keep rescheduling your appointment till the labs are ready."-FGD Discussant, Kumasi, Ashanti

Some stakeholders strongly suggested the need for free medication for all HIV positive children irrespective of the condition. The statement below confirms:

"ooooh for now they don't do the free health insurance registration for them anymore, they don't do that. For me I think that children living with HIV AIDS should have access to free medical care... that is everything. When they are sick and they come to the hospitals, the lab services that is rendered to them should be free, the consultation. [.....] ... yes, if you don't have insurance they have to pay... I know that the LFT (Liver Function Test and the RFT (Renal Function Test) are around 200 Ghana cedes [\$40] then you do full blood count, some places you have to go and do G6PD [...] ... 
errmm lets say once a year you have to do these test... but am even talking about the other conditions."-ART facility manager, Bekwai, Ashanti Region.

Explaining it into detail, the narrative from the ART facility manager with 14 years' experience continued:

"...A child with HIV may come with let's say complicated malaria, the parent hasn't gotten money and am saying that such services should be rendered to the children for free ... Government can say that all children living with HIV should be renewed NHIS premium for free, government must open the scope of services for children under the National Health Insurance."-ART manager, Bekwai, Ashanti region.

\section{Direct supply of food and food supplements}

Consistently running through the desired intervention package for children was the need for food support. While positive caregivers preferred interventions package that included food support in all forms and shapes, ART nutrition practitioners were specific on the request for food supplements. It was desired that the erstwhile intervention in some facilities coded (NACS-Nutritional Status Assessment and Counseling Support) where the nutritional status of the children would be accessed through counseling and further nutritional food supplement offered free be re-instituted by central government and or donors. A statement from a positive mother summed it up:

"So if we get a little help from the government for example, if we are given food stuff like rice, oil and indomie we can manage and feed ourselves even if there is no money." - positive parent of 12 year positive child, Kumasi Ashanti.

The nutritional support component was forcefully reiterated by a nutritional expert who stated:

"I am a nutrition officer and a team player in ART management Okay ... I joined the ART unit from 2011, (8 years) ... I don't think there is any social intervention that any child enjoys, there is no child that I know that is on the Livelihood empowerment against poverty (LEAP). None registers for the health insurance for the children and their caregivers, none that I know, It used to be a package for free from the NACP sponsored by global fund that insures all clients that we register-not only children, but as I said that one has also been scrapped ... 9 since when ohh the last time that we registered their insurance for them was 2015-2016 (3 - 4 years) I have not seen any intervention that is targeted to children alone."-ART Counseling and Nutrition support specialist, Sunyani Brong Ahafo region.

In the opinion of the Nutritional expert, the inclusion of food supplement in any social protection intervention package is needed particularly for children 
under age 5 to address malnourishment situation:

“[...] Errrr, Coming from errrrr, let's say a nutrition point of view, errm I would prefer that preferred that when it comes to vulnerability children are much more vulnerable so when it comes to their nutrition they should be having some nutrition suport... in the form of food supplies because ... errr, it could be factored into the existing programme, there is a programme called which we used to offer them, food NACS+ (Nutrition Status Assessment Counseling and Support Plus) which we used to offer them, foods, blend and RUTF (Ready used therapeutic foods) for those who are malnourished or for those who have lower weight for their ages so but then t like I said that one is too is no longer forthcoming, so children we find wasting we are unable to intervene by way of support, other than to counsel. We do the NACS here but we now do only the counseling without any food support now, but it stopped let's say four years ago (why did it stop), ermmm the support that used to flow ceased and they attributed it to the fire that gut the national medial stores and donor support and all that. In conclusion, Hmm, if the short or medium term the child would be supported in the lets say. So we manage those who are malnourished to probably to also gain their needed health."-ART Counseling and Nutrition support specialist, Sunyani Brong Ahafo region.

Supporting the inclusion of nutritional supplement and food provision in the composition of any social protection policy/programme, an ART nurse manager affirmed that:

“...nutritiona. That's what I was saying because you know that the medications harsh one way or the other so imagine if you skip breakfast eat only lunch and no supper. You see even if... I had a friend who had a prick with those people and he was put on Prep and the side effect she had, it was too much, so personally, imagine you take the [medication] without food... so at least if even they come and we give them something, tm brown, even at the pediatric ward we have tom browns we give to the mothers... But here we don't give unless the person is malnourished."-ART nurse manager, Sunyani Regional Hospital, Brong Ahafo.

In the Ashanti region the facility manager corroborated the need to address both malnourished children and non-malnourished children. This should be a consistent component of any social protection package and not implemented adhoc arbitrary. These concerns were summarized:

"Errm, apart from that, they should also be given nutritional support. For example if we can get an NGO that can provide them foodstuff, that will also go a long way, most of the caregivers are not even working so you realize that the kind of food that the children feed on are not even nutritious visavi taking the Antiretroviral drugs. [...]"-ART Facility Manager, Bek- 
wai, Ashanti region.

When asked whether there is any relationship between diet type and the vulnerability level of positive children, the ART manager explained further that:

"Ohhh Yes!... there is a relationship, because you know the antiretroviral drugs works well on people who are well fed, your food has to be balanced well, once your food is balanced couple with you taking the antiretroviral drugs, gives a good immune response boosted and also it prevent you from getting opportunistic infections. So if a child is not well fed, there are several implications for taking the antiretroviral drugs."-RT Facility Manager, Bekwai, Ashanti region.

\section{Evidenced based targeting of intervention}

The need for evidenced based intervention was mentioned. It was explained that policy should be integrative and should be well thought out backed by evidence of who the real target beneficiaries are or would be:

"The package should be direct and it should go to the benefit of the child. There should be the use of evidence, by getting to the people to know the need, and the implementers should know what is really social welfare package not a package to entice people but one that benefit people."-Municipal Social welfare officer, Sunyani, Brong Ahafo.

\section{Counseling and preferential treatment for children visiting ART for treat-} ment

The need for priority to be given to the treatment of children who attend ART clinic particularly when there were few child specific ART hospitals (in the context of this study only the Komfo Anokye had Adolescent and Child friendly clinic) were itemized. Counseling support was mentioned as a necessary package that ought to be included though it was mentioned there was no formal guideline to guide in the process of disclosure counseling. This view was shared by a senior ART nurse manager:

"What we do is that when somebody comes with a child we give preference to them so to them so they are seen earlier than the normal adult, that's what we used to motivate them and sometimes child counseling and encouraging the caregivers to help them, if it goes extreme we make contributions somehow to support them ... [...] personally I have not met any guideline, but just some normal things that we used to know."-ART nurse manager, Sunyani, Brong Ahafo region.

\section{Discussion}

This study uses an eclectic approach involving several stakeholders' perspectives to explore the nature and type of desired social intervention package for HIV positive children. The dominant themes were interrelated. Our study contends 
and establishes that, the type of social protection policy initiatives that despite the similarity that may be associated with social protection interventions for children in general, a unique set of well-tailored approach and package is to be designed for HIV positive children. The findings in this study reflect the minimum components required for Ghanaian HIV positive children.

The themes that emerged were the need for any social policy/intervention to be inclusive of a disease ending/eradication intervention package, cash transfer for children and their caregivers, free comprehensive [15] health insurance integrating all consultancy and laboratory service charges. The other emerged themes include direct food supplements supply and nutritional support, research, target specified implementation and evidenced based monitoring and counseling support and preferential treatment for children visiting ART for treatment.

Our findings are consistent with the new paradigm of building evidenced based social interventions that meet the needs of the target population as advanced by international best practice. This study reflects a foremost attempt in Ghana to understand what should go into such social interventions for HIV and AIDS infected children by daily programme implementers and direct beneficiaries [3].

The summation of evidence from nearly all stakeholders who matter in designing social protection policy interventions from its conceptualization to programme implementation is a testament to the eclectic nature any comprehensive social protection programming should take both in form and content. The lack of this robustness in designing social protection policy within the Africa region has been bemoaned by Pettifor and others in their studies [2].

The results of this study corrects for the deficit in the design of social protection interventions which leads to an inability to measure their impact or its haphazard implementation missing the target beneficiaries particularly within the HIV context. While previous social protection interventions in Ghana have been carried out for children generically, their design rarely incorporates the specific needs of HIV positive children nor reaches them [16].

The low access to social support and social protection interventions by HIV positive children reflects Jones, Ahadzie and Doh, submissions that social support access to children are extremely low covering only $10 \%$ of the entire Ghanaian population with adults included [16].

This observation comes against the background that despite the entire population of children living with HIV alone would not be reached if they were to be served exclusively with the nations rolled out social intervention programmes. The data shows that the national HIV prevalence is $2.4 \%$, with an estimated number of 29,000 children who are HIV and AIDS infected constituting a 9\% representation of the entire HIV population in Ghana [17].

Thus, a national social protection coverage for less than a $10 \%$ population is not even able to address the entire needs of all HIV infected children and their household. It is in this justification that a tailored specific intervention is needed 
to address the plight of HIV and AIDS infected children. The participants are thus justified in their request for a form and content of social protection package that meets the needs of their client. The findings of this study confirm the need for evidence to anchor any social protection policy design. Our finding is thus consistent with previous findings calling for the use of evidence based interventions and the inclusion of robust indicators in programmes [2] [3].

However, robust indicators can only be included in designing social programmes if the interventions are conceptualized with an integrated research component from conception to implementation and its evaluation. It must be rigorous and in many instances innovative, offering evidence on impacts and/or access [18] [19]. This study established that, for any intervention to be design for HIV and AIDS infected children, research component aimed at evaluating the effects of the intervention should form a core component. Our findings are consistent with the general thematic areas around which social protection interventions should cover as indicated in the systematic review of 26 studies globally. They should revolve around care and support, prevention, treatment, and livelihood promotion [3].

Consistent with the care and support component, our study found that all stakeholders reiterated the need for care and support package reflected in approaches such as cash transfers, free health insurance and medication bills coverage [20]. Thus, the desired outcomes of the stakeholders relative to care and support packages for HIV positive children are in consonance with international best practice. This was expected as the study participants have ample years of working or engaging in caring for HIV positive children whilst the children who were studied had also lived with their illness for some time and could decipher what would work best in their interest to lessen their plight. While our study findings on the desire and call for inclusion of care and support remains welcoming, the reality on policy design for children and elsewhere but particularly in Ghana is that the voices of children are mostly not considered. They are never brought to the discussion table nor included but are expected to be recipients of the policy interventions and design. When attempts are made to include them, they serve only as information recipients. The legal dimension of the principle of evolving capacity and best interest of the child in designing such interventions relative to Article 4 of the Children's charter that need to be acknowledged are rarely taken into consideration [21].

In Ghana, though the national social protection policy has been on the drawing board, evolving from a national social protection strategy into National Social Protection Policy and heralded by the introduction of the cash transfer programme of LEAP (Livelihood Empowerment against Poverty), there was no focus on HIV infected children in its approach [22].

The inclusion criteria did not assume to factor vulnerable HIV infected children who may have their parents alive yet experiencing several degrees of vulnerability. With eligibility criteria being poor household and having at least one 
household child being orphaned or vulnerable child and or with one with extreme disability and elderly poor, it was obvious HIV infected children were more likely to be unreached.

The selection was also to be done through a community based processes with little regard for the inclusion of HIV infected households. In this regard, stigmatisation will make it difficult for the community processes to establish which HIV positive child was vulnerable. The fact remains that HIV is a secretive illness and HIV positive or negative caregivers would not be willing to open up to access a package that gives them a household allowance of 65 cedes (\$13.0) for two months 88 cedes ( $\$ 17.0)$ for 2 families, 96 cedes $(\$ 18.5)$ for three families and 107 cedes ( $\$ 20.5)$ for four households only to face community stigmatization and hands pointing.

There is the need for the involvement of ART clinic staff to be part of the eligibility selection committee to recruit a quota from among HIV infected households who meet the requirements of vulnerability to be eligible for LEAP cash grant. This remains the policy shift required if the design of the social protection interventions are to reach HIV positive children. Our findings integrate the vices of children in the desired social policy package. This may offer some promising returns to address albeit the partially fragmented, and uncoordinated nature of the social policy intervention for children. This will lead to a more comprehensive strategy [23].

The failure of the LEAP programme to address curative care seeking or manageable illness such HIV has been documented by the International Labour Organisation in their systematic review of the 26 social protection intervention for HIV populations and dominantly children [24] [25] [26].

Our findings suggest that only 5 children were enrolled in the LEAP from all the study participants studied and their caregivers and the children themselves. This bemoans the reality on the ground as to whether this intervention is really targeting the most vulnerable population or not.

While, the current LEAP cash grant to vulnerable households in targeted communities will remain a peanut compared to the average living cost, transportation to clinic visit, out of pocket payment for non-insured caregivers of HIV positive children, it was still a preferred component to be integrated in any HIV social intervention package to be designed for HIV positive children.

This request emanates from the popular Ghanaian adage translated to mean that half a loaf is better than none. The study found that the children preferred mostly preventive social intervention package for their illness and were more focused on medication that could cause an end to their plight. While this remains a desired outcome, it is uncertain how a social protection intervention will be able to address that, as medication for HIV eradication may fall outside the scope of social intervention package delivery.

However, the thinking of the children for an eradication policy framework is a wakeup call for governments to commit more resources towards scientific re- 
search aimed at finding a cure to the debilitating HIV illness they face. In the extant literature, much more evidence abound on treatment related social protection intervention packages [3] [19]. However, the only treatment related intervention in our study is the limited in scope. The National Health Insurances however does not cover many aspect of critical care for HIV positive children. It is for this reason that the study participants mutually agreed for a full compressive health coverage to be included in any national social protection package for all HIV positive children. This it was argued: should include all essential health services for HIV children.

Consistent with Temin summative findings from the systematic review conducted, social protection package that hover around food and cash transfer were very effective in mitigating the effect of the illness on children [19]. Our findings are in consonance with an evidence based request. It is however unfortunate that, food transfer that should have been part of previous attempts to design social protection interventions-though uncoordinated, has not factored cash transfer specifically targeted to HIV infected children or their caregivers nor food supply (though some NGOs have been doing it in handful of their intervention sites and ART clinics).

\section{Limitation of the Study}

Our findings are based on the desired expectations of the stakeholder's engaged and their perceptions regarding the desired social protection package for HIV and AIDS positive children. There is the possible risk of response bias. It is possible that the opinions of some of the participants may be informed by their own conceptions particularly around the vulnerability situation of the children and access to the few existing social protection interventions. Any effort to interpret the results to represent the entire nation should be done with caution. The very essence of using the qualitative approach implies that the preference for these minimum social intervention packages may not account for the entire HIV positive children in Ghana.

\section{Conclusions}

In conclusion, this study's findings demonstrate the need to consider the wishes of the most affected in any policy design of what is needed rather than generalizing it. It has been found that the few social protection interventions in Ghana that are supposed to reach out to children in general mostly do not reach out to HIV positive children and in the few cases among those it is able to reach, they are ineffective in addressing their vulnerability levels.

The observation is that, the real needs of HIV positive children; laboratory service, food to the caregivers, cash transfer, counseling and preferential treatment through special clinics for positive children alone, consistent supply of their medications are either not designed, been quasi designed or poorly being implemented. This explains the desires and preference for the inclusion of such 
packages in the design of HIV positive child-focused social intervention framework or policy.

A central theme missing is the need to address the holistic vulnerability levels of these HIV positive children through livelihood support to their caregivers, and this remains lacking in the proposed minimum package. The reasons for the missing out of such all-important and necessary component deserve further investigation [3] [27].

\section{Conflicts of Interest}

The authors declare no conflicts of interest regarding the publication of this paper.

\section{References}

[1] Saul, J., Bachman, G., Allen, S., Toiv, N.F., Cooney, C. and Beamon, T. (2018) The Dreams Core Package of Interventions: A Comprehensive Approach to Preventing HIV among Adolescent Girls and Young Women. PLoS ONE, 13, e0208167. https://doi.org/10.1371/journal.pone.0208167

[2] Pettifor, A., MacPhail, C., Nguyen, N. and Rosenberg, M. (2012) Can Money Prevent the Spread of HIV? A Review of Cash Payments for HIV Prevention. AIDS and Behavior, 16, 1729-1738. https://doi.org/10.1007/s10461-012-0240-Z

[3] McCord, A. and Himmelstine, C.L. (2013) Social Protection and HIV Global Literature Review: Access to Social Protection and Its Impact on People Living with and Affected by HIV and Their Households. International Labour Organization, Geneva.

[4] Dellar, R.C., Dlamini, S. and Karim, Q.A. (2015) Adolescent Girls and Young Women: Key Populations for HIV Epidemic Control. Journal of the International AIDS Society, 18, 19408. https://doi.org/10.7448/IAS.18.2.19408

[5] Toska, E., Gittings, L., Hodes, R., Cluver, L.D., Govender, K., Chademana, K.E., et al. (2016) Resourcing Resilience: Social Protection for HIV Prevention amongst Children and Adolescents in Eastern and Southern Africa. African Journal of AIDS Research, 15, 123-140. https://doi.org/10.2989/16085906.2016.1194299

[6] UNICEF (2006) Africa's Orphaned and Vulnerable Generations: Children Affected by AIDS.

[7] Doku, P.N., Dotse, J.E. and Mensah, K.A. (2015) Perceived Social Support Disparities among Children Affected by HIV/AIDS in Ghana: A Cross-Sectional Survey. BMC Public Health, 15, 538. https://doi.org/10.1186/s12889-015-1856-5

[8] UNICEF, ESARO (2007) Transit to Post-Primary Education with a Spec Focus Girls: Medium-Term Strategies for Developing Post-Primary Education in Eastern and Southern Africa. UNICEF/ESARO, Nairobi.

[9] Townsend, T. (2002) Restructuring and Quality: Issues for Tomorrow's Schools. Routledge, Abingdon-on-Thames.

[10] UNAIDS (2018) Ghana Facts Sheet. Geneva. https://www.unaids.org/en/regionscountries/countries/ghana

[11] Cohen, M.Z., Kahn, D.L. and Steeves, R.H. (2000) Hermeneutic Phenomenological Research: A Practical Guide for Nurse Researchers. Sage Publications, Thousand Oaks. 
[12] Moustakas, C. (1994) Phenomenological Research Methods. Sage Publications, Thousand Oaks. https://doi.org/10.4135/9781412995658

[13] Creswell, J.W. and Miller, D.L. (2000) Determining Validity in Qualitative Inquiry. Theory into Practice, 39, 124-130. https://doi.org/10.1207/s15430421tip3903_2

[14] Angen, M.J. (2000) Evaluating Interpretive Inquiry: Reviewing the Validity Debate and Opening the Dialogue. Qualitative Health Research, 10, 378-395. https://doi.org/10.1177/104973230001000308

[15] Ghana AIDS Commission (2012) Ghana Country Aids Progress. Report Reporting Period January 2010-December 2011. 153 p.

[16] Jones, N., Ahadzie, W. and Doh, D. (2009) Social Protection and Children: Opportunities and Challenges in Ghana. UNICEF WCARO, London.

[17] Ghana AIDS Commission (2017) National and Sub-National HIV and AIDS Estimates and Projections 2017 Report. Accra.

http://www.ghanaids.gov.gh/gac1/pubs/2017-2022_national_and_sub\%20national_ Estimates_Report.pdf

[18] Miller, E. and Samson, M. (2012) HIV-Sensitive Social Protection: State of the Evidence 2012 in Sub-Saharan Africa.

[19] Temin, M. (2010) HIV-Sensitive Social Protection: What Does the Evidence Say. UNAIDS, Geneva.

[20] Holmes, R. and Barrientos, A. (2009) The Potential Role of Cash Transfers in Addressing Childhood Poverty and Vulnerability in West and Central Africa. UNICEF WCARO, London.

[21] Kangaude, G.D. and Skelton, A. (2018) (De)Criminalizing Adolescent Sex: A Rights-Based Assessment of Age of Consent Laws in Eastern and Southern Africa. SAGE Open, 8. https://doi.org/10.1177/2158244018806036

[22] Ministry of Manpower Youth and Employment (2007) LEAP Social Grants Pilot Implementation Design. Summary Report. Accra.

[23] Grebe, E. (2015) The Evolution of Social Protection Policy in Ghana's "Fourth Republic": Contributory Social Insurance Reform and Limited Social Assistance for the "Extreme Poor" under NPP and NDC Governments, 2000-2014.

[24] ILO (2014) Rationalizing Social Protection Expenditure in Ghana. 209 p.

[25] Grebe, E. (2015) The Politics of Social Protection in a Competitive African Democracy: Explaining Social Protection Policy Reform in Ghana (2000-2014).

[26] FAO (2013) Impacts of the LEAP Programme on the Local Economy in Ghana. Rome.

[27] Cantrell, R.A., Sinkala, M., Megazinni, K., Lawson-Marriott, S., Washington, S., Chi, B.H., et al. (2008) A Pilot Study of Food Supplementation to Improve Adherence to Antiretroviral Therapy among Food Insecure Adults in Lusaka, Zambia. Journal of Acquired Immune Deficiency Syndromes, 49, 190-195. https://doi.org/10.1097/QAI.0b013e31818455d2 